\title{
A $\beta$-tubulin 5-derived peptide induces cytotoxic $T$ lymphocytes restricted to the HLA-A24 allele in prostate cancer patients
}

\author{
NOBUKAZU KOMATSU ${ }^{1 *}$, YASUNOBU TERASAKI ${ }^{1,3 *}$, FUKUKO MORIYA $^{2}$, SHIGETAKA SUEKANE $^{2}$, \\ MASANORI NOGUCHI $^{2}$, SATORU TODO $^{3}$, KYOGO ITOH $^{1}$ and SHIGEKI SHICHIJO ${ }^{1}$
}

Departments of ${ }^{1}$ Immunology and Immunotherapy, and ${ }^{2}$ Urology, Kurume University School of Medicine,
Fukuoka 830-0011; ${ }^{3}$ Department of Surgery, Hokkaido University School of Medicine, Hokkaido 060-8638, Japan

Received May 12, 2010; Accepted June 28, 2010

DOI: $10.3892 / \mathrm{etm} .2010 .120$

\begin{abstract}
To facilitate the development of a peptide-based cancer vaccine for prostate cancer patients, we examined whether any of the 13 peptides previously reported to induce HLA-class I-restricted cytotoxic T lymphocyte (CTL) activity in HLA-A3 supertype (-A3, -A11, -A31 and -A33)-positive prostate cancer patients are also capable of inducing CTLs restricted to HLA-A2, HLA-A24 or HLA-A26 alleles. Among the 13 peptides tested, a peptide at positions 309 to 318 of $\beta$-tubulin 5 exhibited binding activity to the HLA-A*2402 molecule and induced HLA-A24-restricted CTL activity against prostate cancer cells derived from peripheral blood mononuclear cells of prostate cancer patients. The CTL activity was determined to be specific to this peptide and was mediated by $\mathrm{CD}^{+} \mathrm{T}$ cells in an HLA-class I-restricted manner. These results suggest that this peptide could be applicable as a peptide vaccine, not only for HLA-A3 supertype-positive, but also for HLA-A24-positive prostate cancer patients.
\end{abstract}

\section{Introduction}

A peptide-based cancer vaccine is one of the new treatment modalities for cancer. We recently reported that it has a clinical benefit for advanced prostate cancer patients in a randomized

Correspondence to: Dr Nobukazu Komatsu, Department of Immunology and Immunotherapy, Kurume University School of Medicine, 67 Asahi-machi, Kurume, Fukuoka 830-0011, Japan E-mail: kom@med.kurume-u.ac.jp

${ }^{*}$ Contributed equally

Abbreviations: CTL, cytotoxic T lymphocyte; DMSO, dimethyl sulfoxide; EBV, Epstein-Barr virus; FBS, fetal bovine serum; HDs, healthy donors; HIV, immunodeficient virus; IFN- $\gamma$, interferon- $\gamma$; PAP, prostate acid phosphatase; PBMCs, peripheral blood mononuclear cells; PHA, phytohemagglutinin

Key words: $\beta$-tubulin 5, peptide, cytotoxic T lymphocyte, HLA-A24, cancer vaccine, peripheral blood mononuclear cell, prostate cancer clinical trial (1). However, peptide-based immunotherapy for cancer patients is highly restricted by HLA-A alleles, which in turn is hampering the development of peptide-based cancer vaccines at the commercial level. Therefore, the identification of candidate peptides widely applicable for patients with different HLA-A alleles is required. We previously found and reported (2-5) such epitope peptides, which bind to more than one HLA-class IA allele. Therefore, in the present study we examined whether or not the 13 different peptides that have been reported to induce HLA-A 3 supertype-restricted cytotoxic T lymphocyte (CTL) activity (2,3,6-10) also induce CTL activity restricted to the HLA-A2, HLA-A24 and HLA-A26 alleles in the peripheral blood mononuclear cells (PBMCs) of prostate cancer patients.

\section{Materials and methods}

Peptide-HLA stabilization assay. To assess the binding and stabilizing activity of peptides to HLA-A*0201, -A*0206, $-A^{*} 0207,-A^{*} 2402$ and $-A^{*} 2601$ molecules, a previously reported method was employed, with several modifications (2,3,6-10). Briefly, RMA-S-A*0201, -A*0206, -A*0207, -A*2402 and -A*2601 (5×105 cells/well in a 24-well plate) were incubated in $500 \mu \mathrm{l}$ RPMI-1640 (Invitrogen) supplemented with $20 \%$ fetal bovine serum (FBS) (MP Biomedicals Inc., Eschwege, Germany) for $20 \mathrm{~h}$ at $26^{\circ} \mathrm{C}$ in $5 \% \mathrm{CO}_{2}$. Then, the cells were incubated in $500 \mu \mathrm{l}$ Opti-MEM (Invitrogen, Carlsbad, CA, USA) containing $0.1-100 \mu \mathrm{M}$ peptides and human $\beta 2$ microglobulin $(2 \mu \mathrm{g} / \mathrm{ml})$ at $26^{\circ} \mathrm{C}$ for $2 \mathrm{~h}$, and then for $3 \mathrm{~h}$ at $37^{\circ} \mathrm{C}$ in $5 \% \mathrm{CO}_{2}$. Cells were washed and incubated for $30 \mathrm{~min}$ on ice with an appropriate dilution of anti-HLA-A24 or BB7.2 supernatant (anti-HLA-A2). After being washed with phosphate-buffered saline (PBS), the cells were stained by Alexa Fluor 488 goat anti-mouse IgG (Invitrogen) for $30 \mathrm{~min}$ on ice. The mean fluorescence intensity (MFI) was measured by flow cytometry, and peptides which exhibited a $>25 \%$ increase in the MFI were defined as positive binding peptides.

Cell lines. The cell lines used as target cells for cytotoxicity were the PC3 (HLA-A*2402) and LNCaP (HLA-A*0201) prostate cancer cell lines, and LNCap transfected with the HLA-A*2402 gene (LNCaP-A24) as previously reported (11). PC3 and LNCaP-A24 tumor cells were used as relevant 
Table I. Characteristics of the prostate cancer patients.

\begin{tabular}{lcccccc}
\hline Patient no. & Age & Gender & TMN category & GS & PSA (before surgery) & PSA (after surgery) \\
\hline 1 & 74 & Male & cT2aN0M0 & $3+4=7$ & 9.99 & 0.348 \\
2 & 65 & Male & T2bN0M0 & $3+4=7$ & 4.11 & 0.529 \\
3 & 76 & Male & & & 5.05 & 0.028 \\
4 & 58 & Male & cT2aN0M0 & $4+4=8$ & 9.09 & $<0.005$ \\
5 & 65 & Male & cT1cN2M0 & $4+3=7$ & 14.70 & 0.006 \\
6 & 66 & Male & cT2aN0M0 & $3+4=7$ & 46.92 & $<0.005$ \\
7 & 75 & Male & cT3bN0M0 & $4+5=9$ & 4.70 & 0.144 \\
8 & 81 & Male & cT1cN0M0 & $3+3=6$ & 7.45 & 0.049 \\
9 & 70 & Male & cT1cN0M0 & $3+4=7$ & & \\
\hline
\end{tabular}

GS, Gleason score; PSA, prostate-specific antigen.

tumor cells for the measurement of HLA-A24-restricted CTL activity, whereas LNCaP cells were used as irrelevant target cells. The cell cultures were maintained in RPMI1640 medium supplemented with 10\% FBS. For the pulsing of peptides to the assessed induction of peptide-specific CTLs from PBMCs as reported previously $(1,8,11)$, we used C1R-A*2402 cells (an HLA-A*2402 gene-stable transfectant of the B lymphoblastoid cell line, kindly provided by Dr M. Takiguchi, Kumamoto University, Japan), as reported previously $(11,12)$. RMA-S cells were derived from a mouse mutant cell line deficient in antigen processing, which showed decreased cell surface expression of MHC class I molecules. The HLA-A*0201, -A*0206, -A*0207, -A*2402 and -A*2601 genes were also individually transfected into RMA-S cells using the FuGENE transfection reagent (Roche, Mannheim, Germany). Clones of stably HLA gene-transfected cells were established from a separate well in the presence of geneticin $(0.5 \mathrm{mg} / \mathrm{ml})$. The detailed methods for establishing these transfectants have been reported previously (7).

Peptides. Peptides with $>90 \%$ purity were purchased from Hokkaido System Science (Sapporo, Japan) or Genenet (Fukuoka, Japan) and dissolved in dimethyl sulfoxide (DMSO) at a concentration of $10 \mu \mathrm{g} / \mathrm{ml}$. Fourteen peptides that were previously shown to be capable of inducing HLA-A3 supertype (-A3, -A11, -A31 and -A33)-restricted CTLs $(2,3,6-10)$ were used in this study. In addition, EpsteinBarr virus (EBV)-derived and human immunodeficient virus (HIV)-derived peptides were used as controls binding to the HLA-A2 and -A24 alleles, as reported previously (13-16). A peptide derived from positions 155 to 163 of prostate acid phosphatase (PAP) was used as a positive control for binding to the HLA-A*0201, $-\mathrm{A}^{*} 0206$ and $-\mathrm{A}^{*} 2402$ alleles, but not the other alleles, as reported previously (2). $\mathrm{NS}_{1582-1590}$ was also used as a positive-control peptide for HLA-A26 (2).

Patients. The Institutional Ethical Review Board of Kurume University approved the study protocol, which conformed to the ethical guidelines of the 1975 Declaration of Helsinki. Informed written consent was obtained from all participants who donated PBMCs for this study. PBMCs were obtained from 9 prostate cancer patients and from 3 healthy donors (HDs) who were homozygous for the HLA-A24 allele. None of the participants were infected with HIV. The patient characteristics are presented in brief in Table I. PBMCs were isolated from blood samples by density centrifugation using Ficoll-Conray (density 1.077), and were cryopreserved until use. The expression of HLA-A24 molecules on PBMCs was discriminated by staining with anti-HLA-A24 mAb and analyzed by flow cytometry (2).

Induction of peptide-specific CTLs from PBMCs. The induction of peptide-specific CTLs and the detection of interferon (INF)- $\gamma$ produced by CTLs were carried out according to a previously reported method with several modifications (6). Briefly, PBMCs $\left(1 \times 10^{5}\right.$ cells per well in a 96-well U-bottomtype plate) were incubated with $10 \mu \mathrm{g} / \mathrm{ml}$ of each peptide in culture medium. The culture medium consisted of $45 \%$ RPMI1640, 45\% AIM-V medium (Invitrogen, Gaithersburg, MD, USA), $10 \%$ FBS, $100 \mathrm{U} / \mathrm{ml}$ interleukin-2 and $0.1 \mathrm{mM}$ MEM Non-Essential Amino Acids Solution (Life Technologies) at $37^{\circ} \mathrm{C}$ in $5 \% \mathrm{CO}_{2}$. On Day 15 of culture, the cells were divided into four wells. Two of these wells were mixed with the corresponding peptide-pulsed C1R-A*2402 cells, while the other two were mixed with the irrelevant (HIV) peptide and incubated for $18 \mathrm{~h}$ at $37^{\circ} \mathrm{C}$ in $5 \% \mathrm{CO}_{2}$. The IFN- $\gamma$ production of CTLs was determined by an enzyme-linked immunosorbent assay. Discrimination of the induction of peptide-specific CTLs was considered to be successful when the P-value was $<0.05$ and when the difference in IFN- $\gamma$ production compared to the control HIV peptide exceeded $50 \mathrm{pg} / \mathrm{ml}$.

Cytotoxicity assay. Peptide-stimulated PBMCs were tested for their cytotoxicity against PC3, LNCaP and LNCap-A24 prostate cancer cells by a standard $6-\mathrm{h}{ }^{51} \mathrm{Cr}$-release assay (2). Phytohemagglutinin (PHA)-activated T cells from HLA-A24positive patients were used as a negative control. The PBMCs were also tested for their cytotoxicity against CIR-A*2401 cells that were pre-pulsed with either a corresponding peptide or the HIV peptide. 
A

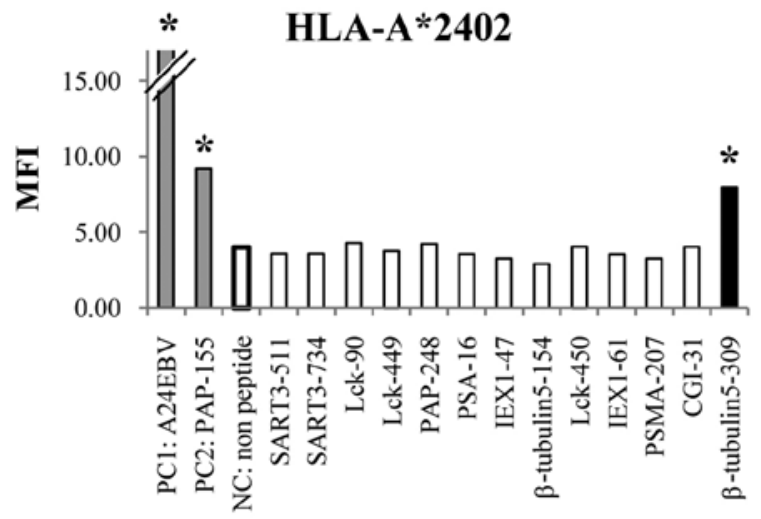

B

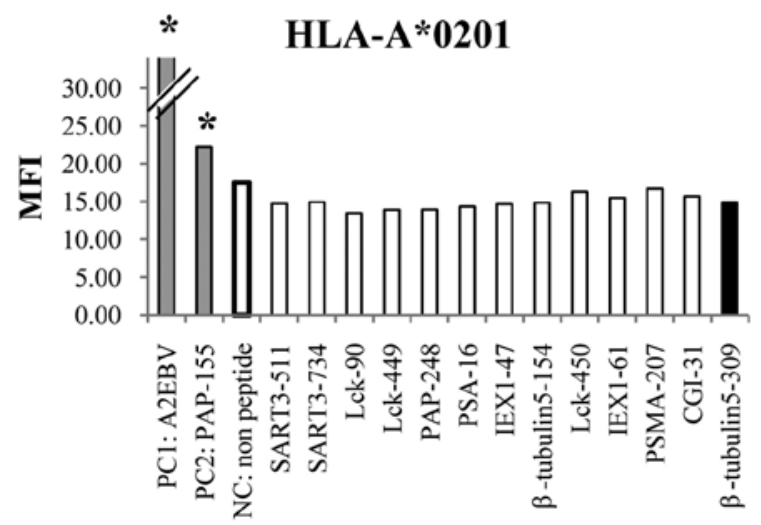

D

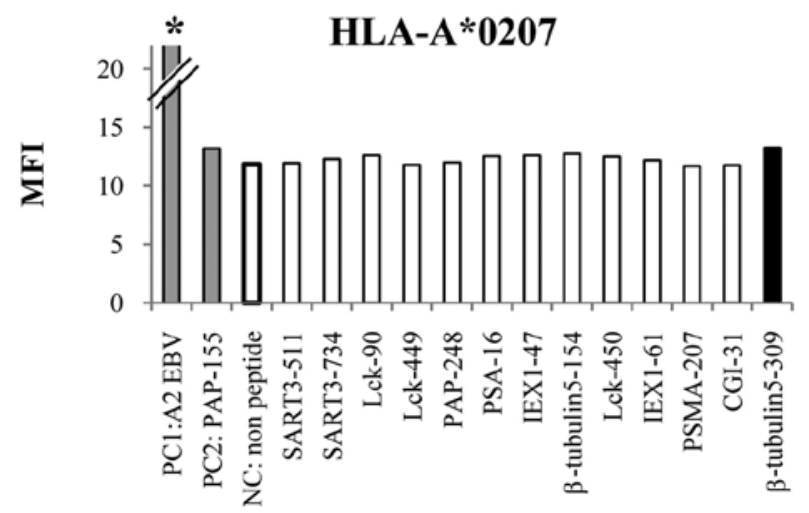

C

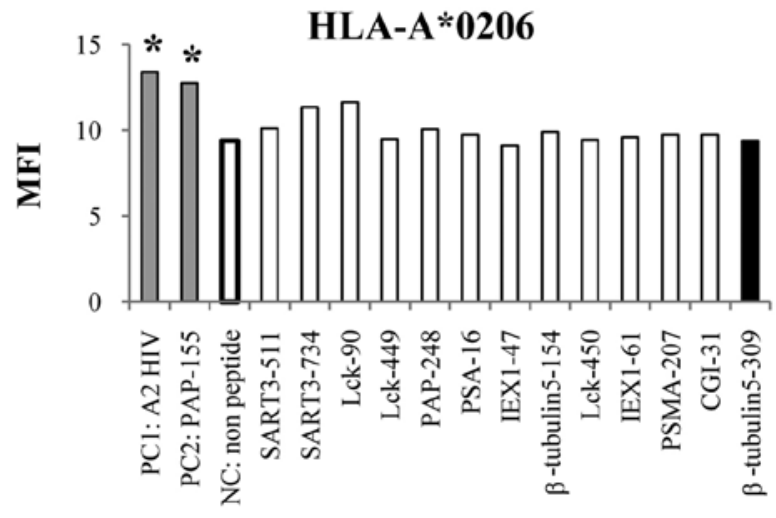

$\mathbf{E}$

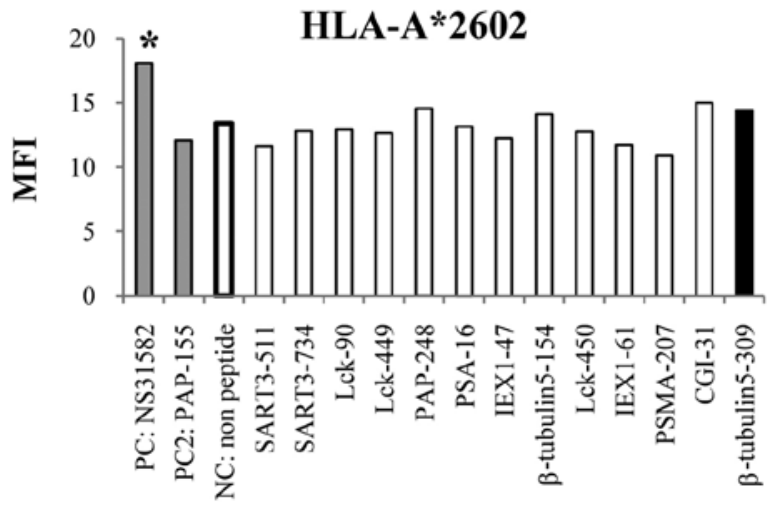

Figure 1. Stabilization assay of the $\beta$-tubulin $5_{309-318}$ peptide for various HLA alleles. The binding activities of the $\beta$-tubulin $5_{309-318}$ peptide to various HLA-A alleles were examined using the stable transfectant cell lines RMA-S-A*0201 (A), -A*0206 (B), -A*2402 (C), -A*0207 (D) and -A*2601 (E) with a positivecontrol peptide and negative control (DMSO). The positive-control peptides used for each HLA were HIV-A2 (A and B), HIV-A24 (C), EBV-A2 (D) and $\mathrm{NS}_{1582-1590}$ (E). A peptide derived from positions 155 to 163 of prostate acid phosphatase (PAP) was used as a positive control for binding to the HLA-A*0201, $-\mathrm{A}^{*} 0206$ and $-\mathrm{A}^{*} 2402$ alleles, but not the other alleles, as reported previously (4). The mean fluorescence intensity (MFI) was indicated at $100 \mu \mathrm{M}$ of the peptide against HLA-A*2402 (A), HLA-A*0201 (B), HLA-*0206 (C), HLA-A*0207 (D) and HLA-A*2602 (E). Representative results from at least three separate experiments are shown. "Statistically significant at $\mathrm{P}<0.05$.

${ }^{51} \mathrm{Cr}$-labeled target cells $(2,000$ cells/well) were mixed with effector cells at the indicated effector-to-target $(\mathrm{E} / \mathrm{T})$ ratios in 96 round-well plates. Immediately before the cytotoxicity assay, $\mathrm{CD}^{+} \mathrm{T}$ cells were positively isolated using a CD8 Positive Isolation kit (Dynal, Oslo, Norway) according to the manufacturer's manual. After incubation for $20 \mathrm{~h}$, the plates were centrifuged and the supernatant was collected to measure radioactive quantitation by a gamma counter. The specific ${ }^{51} \mathrm{Cr}$ release was according to the formula (test cpm - spontaneous cpm). Spontaneous ${ }^{51} \mathrm{Cr}$ release was calculated by measuring the radioactive quantitation of the ${ }^{51} \mathrm{Cr}$-labeled target cell supernatant alone, and the total ${ }^{51} \mathrm{Cr}$ release was then calculated by measuring the radioactive quantitation of ${ }^{51}$ Cr-labeled target cell lysis by $1 \%$ Triton X-100 (Wako Pure Chemical Industries, Osaka, Japan). For the blocking assay, $10 \mu \mathrm{g} / \mathrm{ml}$ of either anti-HLA class I (W6/32: mouse IgG2a), anti-HLA-DR (L243: mouse IgG2a) or anti-HLA-B,C (B1-23, IgG2a; kindly donated by Dr Pierre G. Coulie, Catholique de Louvain University, Brussels, Belgium) was added to the medium at the initiation of the mixed culture. 


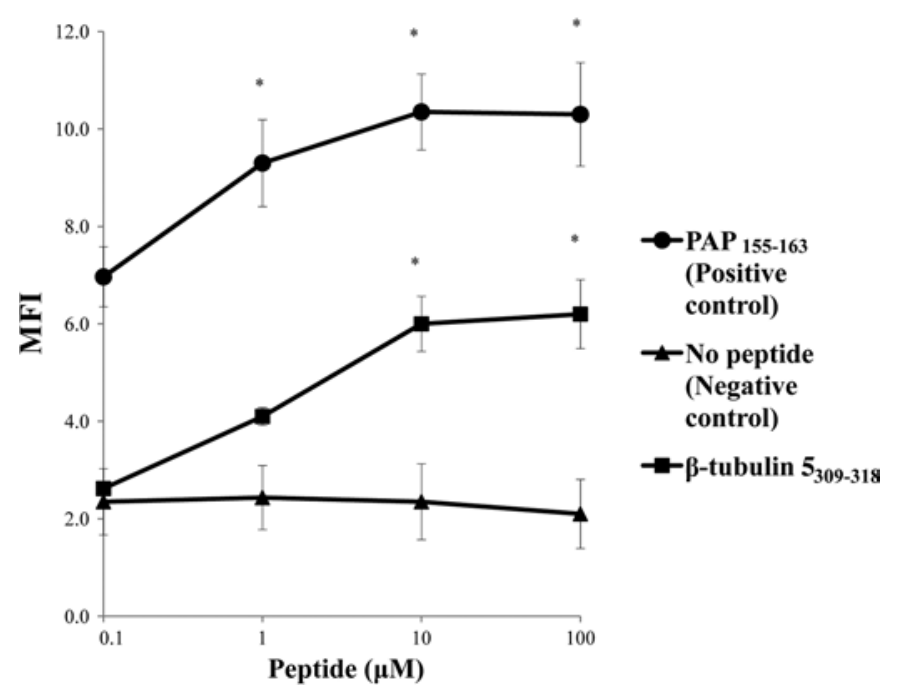

Figure 2. Dose-dependence in the stabilization assay of the $\beta$-tubulin $5_{309-318}$ peptide for the HLA-A*2402 allele. The mean fluorescence intensity (MFI) was recorded at $0.1,1,10$ and $100 \mu \mathrm{M}$ of the peptide or DMSO. The MFI increase induced by the $\beta$-tubulin $5_{309-318}$ peptide compared to DMSO was calculated. Representative results from at least three separate experiments are shown. A PAP-derived peptide at positions 155 to 163 was used as a positive control for binding to the HLA-A*0201, -A*0206 and -A*2402 alleles, but not the other alleles, as reported previously (2). "Statistically significant at $\mathrm{P}<0.05$.

The peptide-stimulated CTLs were confirmed by specific peptide recognition using a cold inhibition assay. In brief, ${ }^{51}$ Cr-labeled target cells $\left(2 \times 10^{4}\right.$ cells per well $)$ were mixed with the effector cells $\left(2 \times 10^{4}\right.$ cells per well) in 96 round-well plates with $2 \times 10^{4}$ cold target cells and peptide-pulsed C1R-A*2402 cells.

Statistical analysis. The Student's t-test was used to test statistical significance, and P-values of $<0.05$ were considered significant.

\section{Results}

HLA stabilization assay. We first screened the binding activity of each of the 13 different HLA-A3 supertype peptides $(100 \mu \mathrm{M})$ to the HLA-A*0201, -A*0206, -A*0207,-A*2402 and -A*2601 alleles by means of an HLA stabilization assay using RMA-S cells expressing each HLA molecule. A PAP-derived peptide consisting of the amino acid sequence from positions 155 to 163 was used as a positive control for binding to the HLA-A*0201, -A*0206 and -A*2402 alleles, but not the other alleles, as reported previously (4). As a result, one peptide from positions 309 to 318 of $\beta$-tublin 5 ( $\beta$-tubulin $5_{309-318}$ ) showed binding activity to HLA-A*2402 molecules, but not to any of the other molecules tested (Fig. 1). The surface expression of the HLA-A*2402 molecules on RMA-S-A*2402 cells was stabilized in a dose-dependent manner when cells were cultured with either a positive control or the $\beta$-tubulin $5_{309-318}$ peptide (Fig. 2).

Induction of peptide-specific CTL activity. We attempted to determine by means of an IFN- $\gamma$ production assay whether or not the $\beta$-tubulin $5_{309-318}$ peptide has the potential
Table II. Interferon- $\gamma$ production in peptide-stimulated prostate cancer patient peripheral blood mononuclear cells.

\begin{tabular}{lcrc}
\hline Patient no. & $\beta$-tubulin 5-309 & $\begin{array}{c}\text { Positive } \\
(\text { EBV })\end{array}$ & $\begin{array}{c}\text { Negative } \\
\text { (HIV) }\end{array}$ \\
\hline 1 & 86 & 51 & NS \\
2 & $\mathrm{~ns}$ & 242 & $\mathrm{NS}$ \\
3 & $\mathrm{~ns}$ & 539 & $\mathrm{NS}$ \\
4 & 50 & $\mathrm{~ns}$ & $\mathrm{NS}$ \\
5 & 50 & 1,501 & $\mathrm{NS}$ \\
6 & 272 & $\mathrm{~ns}$ & $\mathrm{NS}$ \\
7 & 178 & $\mathrm{~ns}$ & $\mathrm{NS}$ \\
8 & $\mathrm{~ns}$ & 457 & $\mathrm{NS}$ \\
9 & $\mathrm{~ns}$ & 50 & $\mathrm{NS}$ \\
\hline
\end{tabular}

EBV, Epstein-Barr virus; HIV, immunodeficient virus; NS, not significant.

to generate peptide-specific CTLs from prostate cancer patients and HDs. PBMCs from HLA-A24/A24 homozygotes were stimulated in vitro with the $\beta$-tubulin $5_{309-318}$ peptide, a positive (EBV) control peptide or a negative (HIV) control peptide, followed by measurement of IFN- $\gamma$ production in response to the appropriate peptide-pulsed cells. The results showed that this peptide induced peptidespecific CTL activity in the PBMCs from 5 of the 9 patients tested (Table II), but not in any of the 3 HDs tested (data not shown). Of the 9 patients, 6 showed CTL activity reactive to the EBV-derived peptide (a positive control), while none showed CTL activity reactive the HIV-derived peptide (a negative control) (Table II).

Cytotoxicity assay. We then determined whether or not the CTLs induced by in vitro stimulation with the $\beta$-tubulin $5_{309-318}$ peptide showed cytotoxicity against prostate cancer cells in PBMCs from 4 of the 5 patients (pt. 1, 4, 6, 7) who exhibited a positive CTL response as indicated by the IFN-release assay (Table II). The peptide-stimulated PBMCs from all 4 of the patients exhibited significant levels of cytotoxicity against both PC3 and LNCaP-A24 cells, but not against LNCaP cells or HLA-A24+ PHA-stimulated T-cell blasts as indicated by the ${ }^{51} \mathrm{Cr}$ release assay (Fig. 3). By contrast, as shown in Table II, PBMCs from none of the 3 patients (pt. 3, 8 and 9) whose samples responded negatively in the IFN $-\gamma$ assay showed detectable levels of CTL activity with this assay (data not shown). The PBMCs from the remaining 3 patients were not eligible for the assay.

We then attempted to identify the cells responsible for the cytotoxicity of $\beta$-tubulin $5_{309-318}$ peptide-stimulated PBMCs. Purified $\mathrm{CD}^{+} \mathrm{T}$ cells were used in the following experiments. The levels of cytotoxicity by $\mathrm{CD}^{+} \mathrm{T}$ cells purified from the peptide-stimulated PBMCs against PC3, as well as LNCaP tumor cells, were significantly decreased by the addition of anti-HLA class I mAb (W6/32), but not by the addition of either anti-HLA class II (HLA-DR) or anti- 
LNCaP-A24

Pt. 1

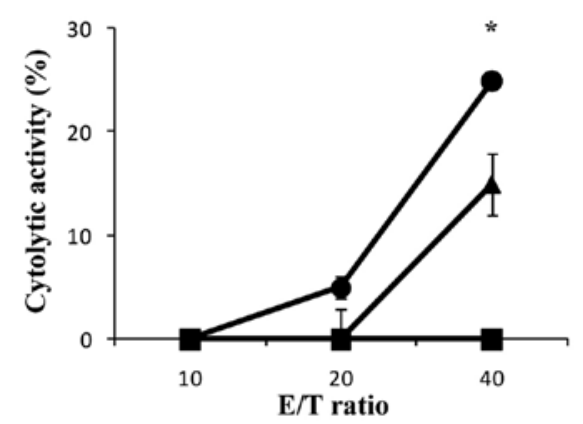

Pt. 4

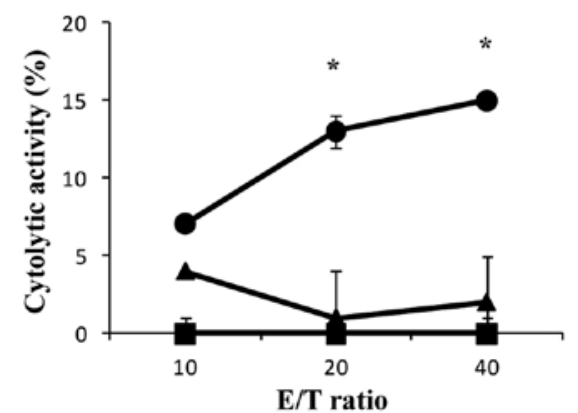

Pt. 6

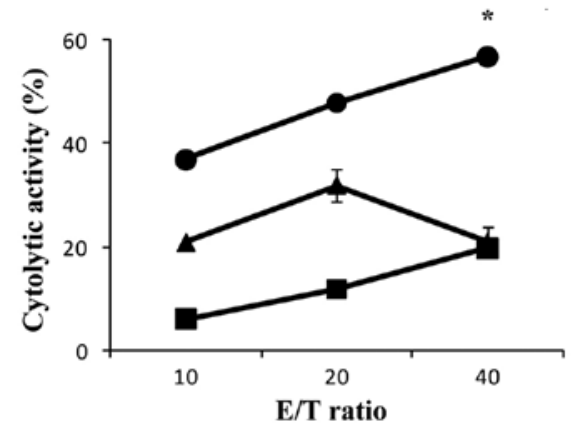

Pt. 7

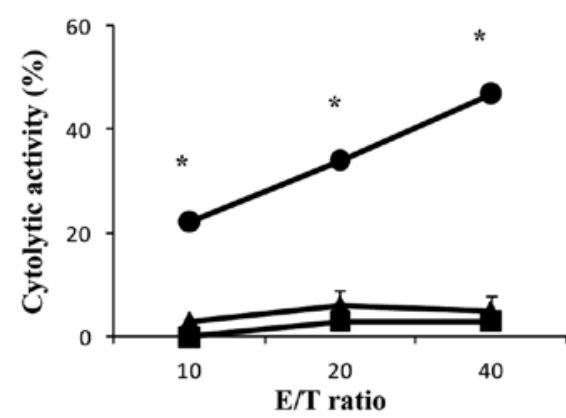

PC3
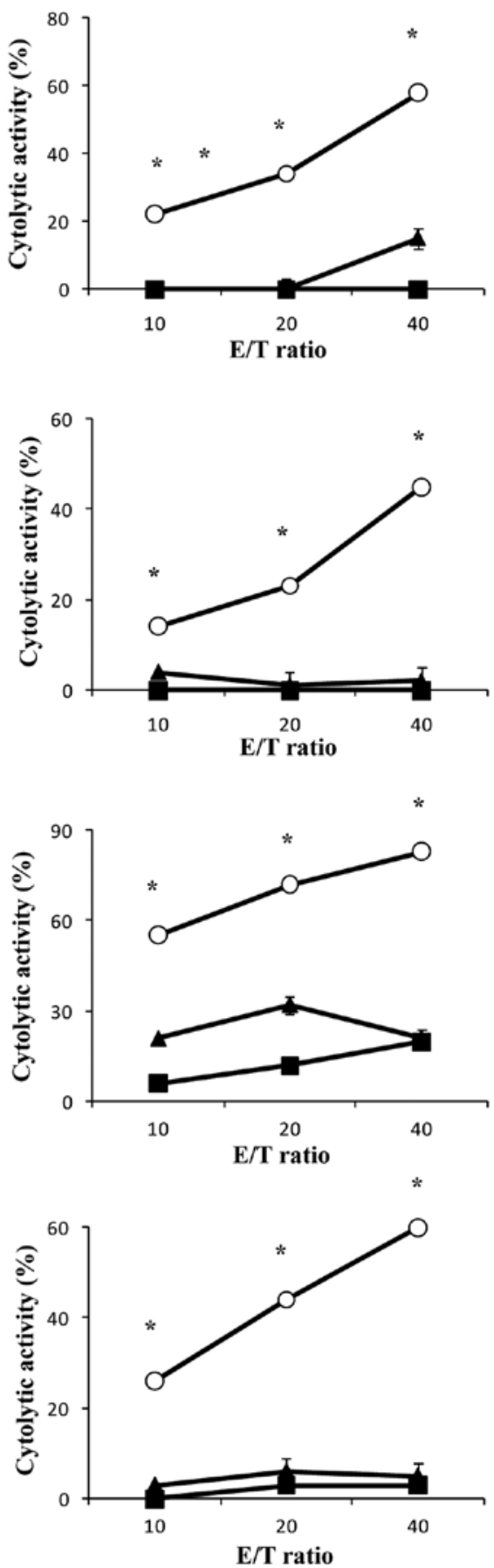

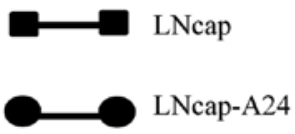

HLA-A24+ PHA-stimulated T-cells

$\underset{\mathrm{PC} 3}{\mathrm{P}}$

Figure 3. The peptide-stimulated PBMCs exhibited significant levels of cytotoxicity against both PC3 and LNCaP-A24 cells. Peptide-stimulated PBMCs from the 4 patients (pt. 1, 4, 6 and 7 of Table II) were tested for their cytotoxicity towards three different targets by a 6-h ${ }^{5} \mathrm{Cr}$-release assay. Phytohemagglutinin (PHA)-stimulated T-cell blasts were derived from PBMCs of HLA-A24+ HDs. *Statistically significant at $\mathrm{P}<0.05$.

HLA-B,C (B1-23, IgG2a) mAbs. Representative cases are shown in Fig. 4A. In addition, cytotoxicity was significantly inhibited by the addition of a corresponding peptide-pulsed unlabeled C1R-A*2402, but not by the addition of an HIV peptide-pulsed unlabeled C1R-A*2402. Representative cases are shown in Fig. 4B. These results indicate that CTL activity was determined to be specific to this peptide, and was mediated by $\mathrm{CD}^{+} \mathrm{T}$ cells in an HLA-class I-restricted manner. 


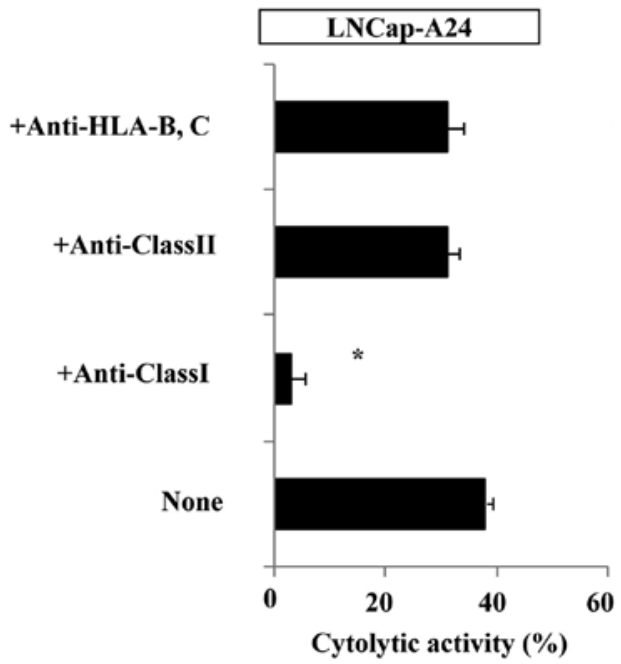

B

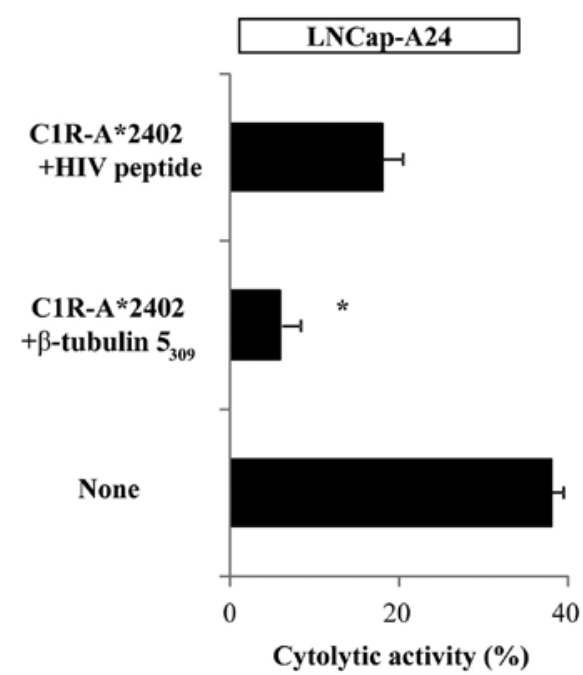

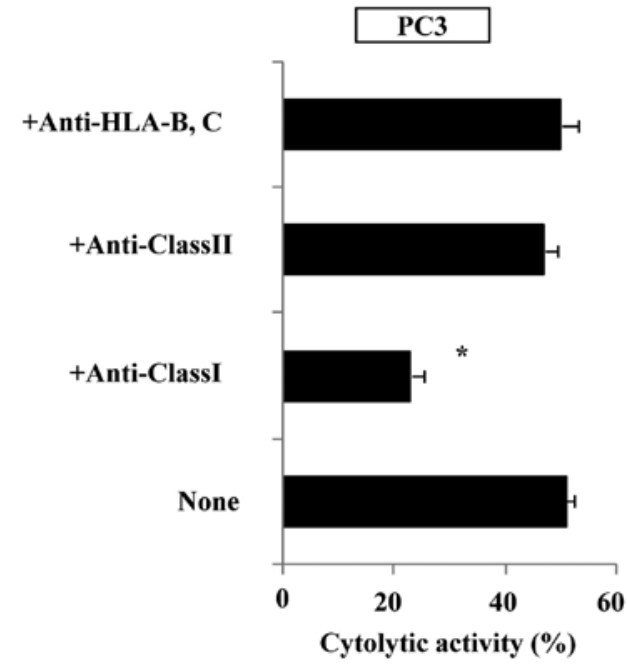

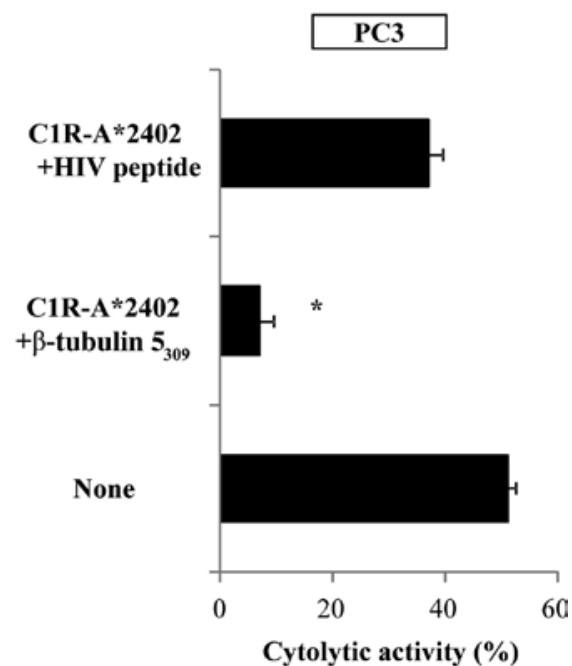

Figure 4. Inhibition assay of peptide-stimulated PBMCs with Abs. (A) Peptide-stimulated PBMCs from 4 patients (patient no. 1, 4, 6 and 7 of Table II) were tested for their cytotoxicity against LNCaP-A24 and PC3 cells in the presence of the indicated monoclonal antibodies. The results of patient no. 1 are presented, and similar results were obtained in the remaining 3 patients (data not shown). (B) Peptide-stimulated PBMCs from 4 patients (patient no. 1, 4, 6 and 7 of Table II) were tested for their cytotoxicity against LNCaP-A24 and PC 3 cells in the presence of unlabeled C1R-A*2402 cells, which were pre-loaded with either the corresponding peptide or the HIV peptide. The results of patient no. 6 are presented, and similar results were obtained in the remaining 3 patients (data not shown). "Statistically significant at $\mathrm{P}<0.05$.

\section{Discussion}

The binding score of the $\beta$-tubulin $5_{309-318}$ peptide (RYLTVAAVFR) to HLA-A*2402 was lower than it was to HLA-A*3101 and -A*3302, but higher than it was to HLA-A3 or $-\mathrm{A}^{*} 1101$, based on information from the BioInformatics and Molecular Analysis Section (BIMAS) website (2). In this study, we showed that the $\beta$-tubulin $5_{309-318}$ peptide, a previously reported peptide capable of inducing HLA-A3 supertype-restricted CTLs (7), did bind to HLA-A*2402, one of the dominant HLA-A types in Asian populations, including the Japanese. HLA-A24 binding peptides are characterized by the presence of $\mathrm{Y}$ or $\mathrm{F}$ residues at amino acid position 2; and of L, F, I or W residues at position $9(12,17)$. These findings suggest that the peptide binds to HLA-A*2402 molecules. On the other hand, no binding of this peptide to HLA-A0201transfected cells was expected, since its binding score to HLA-A*0201 on BIMAS is zero. Indeed, $\beta$-tubulin $5_{309-318}$ showed no binding activity to the HLA-A*0201, -A*0206 or -A*0207 molecules.

We previously reported that the use of the CTL assay with a 14-day incubation period and with stimulation administered five times did not detect CTL precursors by de novo sensitization to an epitope peptide (18). The sensitivity of this employed CTL assay was 1 out of 3,000 to 1 out of 5,000 CTL precursors. Thus, it is likely that the immune response against the $\beta$-tubulin $5_{309-318}$ peptide is relatively restricted in cancer patients whose tumors overexpress $\beta$-tubulin 5 antigen (19-21). This is primarily because naïve T cells from HDs do not induce CTL activity as readily as those from prostate cancer patients. Indeed, PBMCs from any of the three HDs homozygous for the HLA-A24 allele showed CTL activity (data not shown). By contrast, it was relatively easy to induce $\beta$-tubulin $5_{309-318^{-}}$ specific CTLs in prostate cancer patients, and such CTLs were detectable in 5 of the 9 patients tested. CTL precursors were not detectable in the remaining 4 patients, which may have 
been due, in part, to the immune suppression associated with prostate cancer. Alternatively, the employed CTL assays may not have been sufficiently sensitive, based on the finding that the CTL precursors to the EBV-derived peptide, which were used as a positive control, were also detectable in some of the patients tested.

Significantly higher fractions of $\beta$-tubulin class II and V mRNA were reported as compared to the other isotypes in lung tumor samples (22). In regard to biological function, $\beta$-tubulin 5 , which is located in the cytoplasm and one of the structural subunit of microtubules, is important for cell proliferation (19). Tubulin is one of the major target molecules of anticancer drugs such as docetaxel, based on the fact that the expression of tubulin is reported more often in cancer cells than in normal cells (19-21).

Together with the results presented herein, these findings suggest that the $\beta$-tubulin 5 peptide has potential utility as a cancer vaccine, both in prostate and other types of cancer.

\section{Acknowledgements}

This study was supported in part by Grants-in-Aid from the Ministry of Education, Science, Sports and Culture of Japan (no. 12213134 to K.I., no. 21591652 to S.S. and no. 18591449 to M.N.), and by the Toshi-Area Program (to K.I., S.S. and M.N.).

\section{References}

1. Noguchi N, Kakuma T, Uemura H, et al: A randomized phase II trial of personalized peptide vaccine plus low dose estramustine phosphate (EMP) versus standard dose EMP in patients with castration resistant prostate cancer. Cancer Immunol Immunother 59: 1001-1009, 2010.

2. Terasaki Y, Shichijo S, Nui Y, et al: An HLA-A3-binding prostate acid phosphatase-derived peptide can induce CTLs restricted to HLA-A2 and -A24 alleles. Cancer Immunol Immunother 58: $1877-1885,2009$.

3. Mohamed RE, Naito M, Terasaki Y, et al: Capability of SART $_{3109-118}$ peptide to induce cytotoxic T-lymphocytes from prostate cancer patients with HLA class I-A11, -A31 and -A33 alleles. Int J Oncol 34: 529-536, 2009.

4. Niu Y, Komatsu N, Komohara K, et al: A peptide derived from hepatitis $\mathrm{C}$ virus (HCV) core protein inducing cellular responses in patients with HCV with various HLA class IA alleles. J Med Virol 81: 1232-1240, 2009.

5. Niu Y, Terasaki Y, Komatsu N, Noguchi M, Shichijo S and Itoh $\mathrm{K}$ : Identification of peptides applicable as vaccines for HLA-A26positive cancer patients. Cancer Sci 100: 2167-2174, 2009.

6. Matsueda S, Takedatsu H, Yao A, et al: Identification of peptide vaccine candidates for prostate cancer patients with HLA-A3 supertype alleles. Clin Cancer Res 11: 6933-6943, 2005.
7. Takedatsu H, Shichijo S, Katagiri K, Sawamizu H, Sata M and Itoh K: Identification of peptide vaccine candidates sharing among HLA-A $3^{+},-\mathrm{A} 11^{+},-\mathrm{A} 31^{+}$, and $-\mathrm{A} 33^{+}$cancer patients. Clin Cancer Res 10: 1112-1120, 2004.

8. Minami T, Matsueda S, Takedatsu H, et al: Identification of SART3-derived peptides having the potential to induce cancerreactive cytotoxic $\mathrm{T}$ lymphocytes from prostate cancer patients with HLA-A3 supertype alleles. Cancer Immunol Immunother 56: 689-698, 2007.

9. Matsueda S, Takedatsu H, Sasada T, et al: New peptide vaccine candidates for epithelial cancer patients with HLA-A3 supertype alleles. J Immunother 30: 274-281, 2007.

10. Naito M, Komohara Y, Ishihara Y, et al: Identification of Lck-derived peptides applicable to anti-cancer vaccine for patients with human leukocyte antigen-A3 supertype alleles. $\mathrm{Br}$ J Cancer 97: 1648-1654, 2007.

11. Yao A, Harada M, Matsueda S, et al: Identification of parathyroid hormone-related protein-derived peptides immunogenic in human histocompatibility leukocyte antigen-A $24^{+}$prostate cancer patients. Br J Cancer 91: 287-296, 2004.

12. Torikai H, Akatsuka Y, Miyauchi H, et al: The HLA-A*0201restricted minor histocompatibility antigen $\mathrm{HA}-1 \mathrm{H}$ peptide can also be presented by another HLA-A2 subtype, A*0206. Bone Marrow Transplant 40: 165-174, 2007.

13. Steven NM, Annels NE, Kumar A, Leese AM, Kurilla MG and Rickinson AB: Immediate early and early lytic cycle proteins are frequent targets of the Epstein-Barr virus-induced cytotoxic T cell response. J Exp Med 185: 1605-1607, 1997.

14. Lee SP, Tierney RJ, Thomas WA, Brooks JM and Rickinson AB: Conserved CTL epitopes within EBV latent membrane protein 2. A potential target for CTL-based tumor therapy. J Immunol 158: 3325-3334, 1997.

15. Parker KC, Bednarek MA, Hull LK, et al: Sequence motifs important for peptide binding to the human MHC class I molecule, HLA-A2. J Immunol 149: 3580-3587, 1992.

16. Ikeda-Moore $\mathrm{Y}$, Tomiyama $\mathrm{H}$, Miwa $\mathrm{K}$, et al: Identification and characterization of multiple HLA-A24-restricted HIV-1 CTL epitopes: strong epitopes are derived from V regions of HIV-1. J Immunol 159: 6242-6252, 1997.

17. Rammensee HG, Flak K and Rotzschke O: Peptides naturally presented by MHC class I molecules. Annu Rev Immunol 11: 213-244, 1993.

18. Hida N, Maeda Y, Katagiri K, Takasu H, Harada M and Itoh K: A simple culture protocol to detect peptide-specific cytotoxic $\mathrm{T}$ lymphocyte precursors in the circulation. Cancer Immunol Immunother 51: 219-228, 2002.

19. Jordan MA and Wilson L: Microtubules and actin filaments: dynamic targets for cancer chemotherapy. Curr Opin Cell Biol 10: 123-130, 1998.

20. Hashimoto Y, Tajima O, Hashiba H, Nose K and Kuroki T: Elevated expression of secondary, but not early, responding genes to phorbol ester tumor promoters in papillomas and carcinomas of mouse skin. Mol Carcinog 3: 302-308, 1990.

21. Kato K, Ito H, Inaguma Y, Okamoto K and Saga S: Synthesis and accumulation of $\alpha \mathrm{B}$ crystallin in C6 glioma cells is induced by agents that promote the disassembly of microtubules. J Biol Chem 271: 26989-26994, 1996.

22. Cucchiarelli V, Hiser L, Smith $\mathrm{H}$, et al: Beta-tubulin isotype classes II and $\mathrm{V}$ expression patterns in non-small cell lung carcinomas. Cell Motil Cytoskeleton 65: 675-685, 2008. 